\title{
Superoxide Dismutase and Glutathione Peroxidase Levels in Patients with Long Standing Type 2 Diabetes in Port Harcourt, Rivers State, Nigeria
}

\author{
Ojoye Ngoye Briggs ${ }^{1}$, Holy Brown ${ }^{2}$, Kemzi Elechi-amadi ${ }^{3}$, Ferdinand Ezeiruaku ${ }^{4}$, Nsirim Nduka ${ }^{5}$ \\ ${ }^{1,2,3,5}$ Department of Medical Laboratory Science, Rivers state University of Science and Technology, Nkpolu-Oroworukwo, Port Harcourt, \\ Nigeria
}

${ }^{4}$ Department of Medical Laboratory Science, Niger Delta University, Wilberforce Island, Bayelsa State, Nigeria

\begin{abstract}
Diabetes mellitus (DM) is a group of metabolic diseases characterized by hyperglycaemia resulting from defects in insulin secretion, insulin action, or both. It is associated with increased oxidative stress. This study evaluates the levels of the antioxidant enzymes superoxide dismutase (SOD) and gluthathione peroxidase (GPx), as a measure of antioxidant status in Type 2 diabetics. A total of 182 subjects were involved in the study, of which 109 were diabetics (Test) and 73 non-diabetics (Controls). The criterion for the classification as a diabetic was based on subjects having glycated haemoglobin (HbA1c) levels $\geq 6.5 \%$. A structured interviewer administered questionnaire was used as an aid in the collection of demographic and lifestyle data from the subjects. HbA1c was estimated quantitatively by immunochemical method. SOD and GPX was measured by the sandwich-enzyme linked immunosorbent assay (ELISA) method. Glucose oxidase method was used for the determination of fasting plasma glucose (FPG). Mean SOD and GPx values in the diabetic subjects were significantly lower $(p<0.05)$ as compared with that of the controls. Also, there were significant decreases $(p<0.05)$ in the levels of the enzymes with increasing years of illness. There were no significant differences ( $>>0.05)$ in the levels of SOD and GPX in diabetic subjects with respect to age differences, even though the enzyme levels decreased with increasing age. FPG and HbA1c levels were significantly higher $(p<0.05)$ in the diabetics as compared to the controls. Type 2 diabetes is associated with decreased antioxidative status as the levels of the antioxidant enzymes SOD and GPX were significantly reduced in the diabetic subjects. The increasing duration of the illness further depresses the antioxidative system. As the disease condition progresses, antioxidative parameters are further depleted, showing an increase in oxidative stress. It is thus recommended that antioxidative therapy be incorporated in the management/therapy of Type 2 diabetics, to supplement the endogenous anti-oxidative system, as this could prevent or delay progression of the disease and the development of late diabetic complications.
\end{abstract}

Keywords: Diabetes mellitus, Superoxide dismutase, Glutathione peroxidase, Antioxidants, Hyperglycaemia.

\section{Introduction}

Diabetes mellitus (DM) is a group of metabolic diseases/syndromes characterized by hyperglycaemia resulting from defects in insulin secretion, insulin action, or both. The characteristic chronic hyperglycaemia is associated with long-term damage, dysfunction, and failure of different organs, especially the eyes, kidneys, nerves, heart, and blood vessels. There is altered metabolism of carbohydrates, lipids, and proteins along with an increased risk of complications from vascular disease (ADA, 2010). Diabetes mellitus has taken its place as one of the most important diseases worldwide, reaching epidemic proportions and global estimates predict that the proportion of adult population with diabetes will increase $69 \%$ for the year 2030 (Shaw et al., 2010). Increasing evidence suggests that oxidative stress plays a role in the pathogenesis of diabetes mellitus and its complications (Brownlee, 2001). Hyperglycaemia increases oxidative stress, which contributes to the impairment of the main processes that fail during diabetes, insulin action and insulin secretion (Rains \& Jain, 2011). Although obesity and physical inactivity are known to be the leading factors for the development of Type 2 diabetes mellitus, recent evidence suggests that oxidative stress may contribute to its pathogenesis by increasing insulin resistance or impairing insulin secretion (Montonen et al., 2004).
To protect the cells and organ systems of the body against reactive oxygen species (ROS), humans have evolved a highly sophisticated and complex antioxidant protection system. It involves a variety of components, both endogenous and exogenous in origin that function interactively and synergistically to neutralize free radicals (Mark, 1998). This system consists of enzymatic and non enzymatic antioxidants that work together to prevent free radical damage. Some of the antioxidant enzymes that are found to provide a protection against ROS are Superoxide dismutases (SOD), Glutathione peroxidases (GPx) and Catalases (CAT), in addition to numerous non-enzymatic small molecules distributed widely in the biological system and capable of scavenging free radicals. Antioxidants help repair damage done by free radicals and the resulting oxidation; these enzymes however, go a step further by attempting to stop damage before it occurs by triggering chemical reactions that rid the body of free radicals and ROS (Krishnamurthy \& Wadhwani, 2012). SOD, GPx and CAT are the enzymes with the most antioxidant activity and thus considered the main antioxidant enzymes that regulate free radical activity. They constitute a mutually supportive team of defence against ROS. SOD is considered a first-line defence against ROS and is present in nearly all cells. It converts superoxide ion $\left(\mathrm{O}_{2}^{-}\right)$to hydrogen peroxide $\left(\mathrm{H}_{2} \mathrm{O}_{2}\right)$. As the $\mathrm{H}_{2} \mathrm{O}_{2}$ may still react with other ROS, it needs to be degraded by either one of the other two antioxidant enzymes, GPx or CAT. GPx removes $\mathrm{H}_{2} \mathrm{O}_{2}$ by coupling its reduction with the oxidation of glutathione (GSH). GPx can 


\section{International Journal of Science and Research (IJSR) \\ ISSN (Online): 2319-7064 \\ Index Copernicus Value (2013): 6.14 | Impact Factor (2014): 5.611}

also reduce other peroxides, such as fatty acid hydroperoxides. CAT which is localized primarily in peroxisomes, detoxifies the $\mathrm{H}_{2} \mathrm{O}_{2}$ converting it into water and molecular oxygen (Krishnamurthy \& Wadhwani, 2012).

Type 2 diabetes is accompanied with increased formation of free radicals leading to oxidative damage of cell components (Bashan et al., 2009), and ROS production in diabetes plays a key role in the pathogenesis of diabetic complications (Brownlee, 2001). ROS accelerates important molecular mechanisms involved in hyperglycaemia induced oxidative damage; it increases the stress signalling pathways that lead to beta-cell apoptosis (Rhodes, 2005). Hence the need to measure the antioxidant status of Type 2 diabetics.

Free radicals affect the insulin signalling cascade (Rains \& Jain, 2011). As with other ROS effects, low doses play physiological roles in insulin signalling. After insulin stimulation of its receptor in adipocytes, $\mathrm{H}_{2} \mathrm{O}_{2}$ is produced via nicotinamide adenine dinucleotide phosphate (NADPH) oxidase inhibiting protein-tyrosine phosphatase 1B (PTP1B) catalytic activity, thus increasing tyrosine phosphorylation (Mahadev et al., 2004). However, oxidative stress caused by hyperglycaemia in diabetes may impair insulin signalling, leading to insulin resistance and although no mechanisms have been completely established, several responses to ROS excess in the insulin signalling have been proposed. Disturbances in cellular redistribution of insulin signalling components may alter the insulin cascade, a process mediated by nuclear factor kappa-B (NF-кB). A decrease in glucose transporter Type 4 (GLUT4) gene transcription and increase in glucose transporter Type 1 (GLUT1) (insulin independent glucose transporter) has also been observed, as well as increases in phosphorylation of Insulin receptor substrate (IRS) protein in an insulin receptor-independent fashion (perhaps by the stress kinases). Altogether, hyperglycaemia and insulin resistance may also lead to mitochondrial dysfunction and insulin action impairment by cytokines in response to metabolic stress (Bloch-Damti \& Bashan, 2005). An increase in the hexosamine pathway has also been linked to insulin resistance. It has been proposed that this pathway acts as a cellular sensor for the glucose excess. Thus insulin resistance may be a protective mechanism from the glucose excess entrance (Buse, 2006).

Pancreatic beta-cells are especially sensitive to ROS and other free radicals. This is because their natural enzymatic antioxidant defences are lower compared to other tissues such as liver. Also, they lack the ability to adapt their low enzyme activity levels in response to stress such as high glucose or high oxygen (Tiedge et al., 1997). Glucose enters the beta-cell in an insulin independent fashion, because besides providing energy, glucose sensing in the beta-cell is crucial for insulin secretion. It has been suggested that hyperglycaemia can generate chronic oxidative stress by the glucose oxidation pathway, leading to an excess in mitochondrial superoxide $\left(\mathrm{O}_{2}^{-}\right)$production, which further activates uncoupling protein-2 (UCP-2). This protein lowers adenosine triphosphate (ATP)/adenosine diphosphate (ADP) relationship through proton leak in the beta-cell, thereby reducing insulin secretion (Brownlee, 2003). ROS increases the stress signalling pathways in the beta cells such as; the $\mathrm{NF}-\kappa \mathrm{B}$ activity, which potentially leads to beta-cell apoptosis (Rhodes, 2005), and the c-Jun N-terminal kinases (JNK) pathway which has been related to suppression of insulin gene expression, possibly by reduction of pancreatic and duodenal homeobox factor-1 (PDX-1) DNA binding activity, a major regulator of insulin expression (Kaneto et al., 2005). It has also been shown that the activation of the hexosamine pathway in beta-cells leads to suppression of PDX-1 binding to the insulin and other genes involved in insulin secretion, perhaps contributing to the beta-cell dysfunction present in diabetes mellitus (Kaneto et al., 2001). As in other cell types, nitric oxide (NO) has physiologic roles in beta-cells. NO may regulate glucokinase activity by s-nitrosilation in the beta-cell, and possibly increase insulin secretion (Rizzo \& Piston, 2003). However, NO excess and concomitant nuclear receptor signalling (NRS) may cause apoptosis through caspase-3 activation and decrease in ATP levels. Besides ROS hyperproduction, excess mitochondrial metabolism resulting form hyperglycaemia in the beta-cell may also alter mitochondrial shape, volume and behaviour, uncoupling potassium (K)ATP channels from mitochondrial activity and thus altering glucose-induced insulin secretion (Drews et al., 2010).

Several studies have shown that diabetes mellitus (Types 1 and 2) is accompanied by increased formation of free radicals and decreased antioxidant capacity, leading to oxidative damage of cell components (Bashan et al., 2009) There are multiple sources of ROS production in diabetes mellitus including those of mitochondrial and nonmitochondrial origins. The mitochondrial respiratory chain is a non-enzymatic source of ROS. Hyperglycaemia-induced generation of free radicals at the mitochondrial level is thought to be the major driver of the vicious cycle of oxidative stress in diabetes. Increased intracellular glucose leads to an abundance of electron donors generated during the Kreb's cycle. This drives the inner mitochondrial membrane potential upward, a state that is associated with mitochondrial dysfunction and increased ROS production. The augmented generation of pyruvate via accelerated glycolysis under hyperglycaemic conditions is thought to flood the mitochondria and thus generates ROS formation at the level of complex II in the respiratory chain. Thus mitochondrial superoxide production plays a central role in the pathogenesis of diabetic complications (Brownlee, 2001). The production of ROS is reduced by using either an uncoupler of oxidative phosphorylation or by the overexpression of either uncoupling protein-1 or manganesesuperoxide dismutase (MnSOD), such that normalizing the levels of mitochondrial ROS with any of these agents will prevent glucose-induced activation of protein kinase C, formation of advanced glycation-end products, sorbitol accumulation, and NF- $\kappa \mathrm{B}$ activation. These findings support the feasibility of targeting the triggering role of mitochondrial superoxide production in hyperglycaemiainduced tissue damage (Nishikawa et al., 2000).

Under diabetic conditions, reactive oxygen species (ROS) are produced mainly through the glycation reaction which occurs in various tissues and may play a role in the development of complications in diabetes (Brownlee, 2001). Although the induction of the glycation reaction in diabetes was originally found in neural cells and the lens crystalline, which are also known targets of diabetic complications, 


\section{International Journal of Science and Research (IJSR) \\ ISSN (Online): 2319-7064 \\ Index Copernicus Value (2013): 6.14 | Impact Factor (2014): 5.611}

another target was recently shown to be the beta-cell. Indeed, advanced glycation end products (AGEs) were shown to be detectable in beta-cells kept under high glucose concentrations, and the level of 8-hydroxy-2deoxyguanosine (8-OHdG), a marker for oxidative stress, is increased in beta-cells of diabetic Goto-Kakizaki (GK) rats (Ihara et al., 1999). Also the expression of antioxidant enzymes, such as superoxide dismutase, catalase, and glutathione peroxidase, is known to be very low in islet cells compared with other tissues and cells (Tiedge et al., 1997). Therefore, once beta-cells face oxidative stress, they may be rather sensitive to it, suggesting that glycation and subsequent oxidative stress may in part mediate the toxic effect of hyperglycaemia. As direct support for this, it has being shown that glycation-mediated ROS production reduces insulin gene transcription and also causes apoptosis of beta-cells (Kaneto et al., 1996).ROS accelerates important molecular mechanisms involved in hyperglycaemia induced oxidative tissue damage. These molecular pathways are involved in ROS formation and ROS induced damage. They are related to oxidative stress in diabetes and most of them are linked to glucose and/or lipid metabolism. The pathways are; activation of protein kinase $\mathrm{C}$ (PKC), increased hexosamine pathway flux, increased advanced glycation end-product (AGE), increased polyol pathway flux etc (Rolo \& Palmeira, 2006).

\section{Materials and Methods}

\subsection{Study Design}

182 subjects age and sex matched made up the study population. 73 apparently healthy non-diabetics were used as controls and 109 diabetics used as test subjects. All subjects were advised to be on 10 to 14 hours overnight fast prior to collection of samples. The test subjects (diabetics) were those whose glycated haemoglobin (HbA1c) values were $\geq$ (greater than or equal to) 6.5\% and the control subjects (nondiabetics) were those whose HbA1c values were < (less than) $6.5 \%$ (WHO, 2011; ADA, 2015). Informed consent was obtained from all subjects and a structured interviewer administered questionnaire was used to collect data such as age and duration of illness.

Proper vene puncture technique was employed in the collection of the blood samples. All reagents were commercially purchased and the manufacturer's standard operating procedures were strictly followed. Fasting plasma glucose (FPG) was estimated quantitatively using the Glucose oxidase method as modified by Randox laboratories limited (United Kingdom). HbA1c levels were estimated quantitatively using immunoassay method as described by
Chek diagnostics (United State of America). SOD and GPx levels were estimated quantitatively by the sandwichenzyme linked immunosorbent assay (ELISA) method as modified by Elabscience Biotechnology Company limited (China).

Data generated were analysed using Statistical Package for Social Sciences (SPSS), and Microsoft Office Excel 2007. Comparisons of mean and standard deviation values were made for the various parameters for test and control subjects using the "student" $\mathrm{t}$ - test and the analysis of variance (ANOVA). Results were considered statistically significant at $95 \%$ confidence interval ( $p<0.05)$.

\section{Results}

Table 1: Showing results of FPG, HbA1c, SOD, and GPx of diabetic and control subjects.

\begin{tabular}{|c|c|c|c|c|}
\hline & FPG(mmol/l) & HbA1c(\%) & SOD(pg/ml) & GPx(ng/ml) \\
\hline Control N=73 & $4.58 \pm 0.69$ & $5.48 \pm 0.57$ & $57.24 \pm 16.23$ & $1.28 \pm 0.59$ \\
\hline DM N=109 & $8.14 \pm 3.9$ & $8.65 \pm 2.21$ & $48.30 \pm 24.16$ & $0.79 \pm 0.58$ \\
\hline p-value & $<0.0001$ & $<0.0001$ & 0.003229 & $<0.0001$ \\
\hline
\end{tabular}

Values are expressed as mean \pm SD

$\mathrm{N}$ - Number of subjects.

The results in Table 1 above show that the mean FPG levels of the diabetic subjects was significantly higher $(\mathrm{p}<0.05)$ when compared with that of the control subjects. Also the mean value of HbA1c concentrations for the diabetics was significantly higher $(\mathrm{p}<0.05)$ than that of the control subjects. SOD and GPX values of diabetics were significantly lower $(\mathrm{p}<0.05)$ as compared with that of the control subjects.

Table 2: Showing ANOVA results of SOD and GPx levels in diabetic subjects with respect to duration of illness

\begin{tabular}{|c|c|c|}
\hline Duration of Illness(yrs) & SOD(pg/ml) & GPx(ng/ml) \\
\hline 0 -5yrs N=38 & $69.98 \pm 27.37$ & $1.18 \pm 0.79$ \\
\hline 6-10yrs N=42 & $36.16 \pm 10.80$ & $0.51 \pm 0.16$ \\
\hline $11-15 y r s ~ N=26$ & $37.7 \pm 10.69$ & $0.63 \pm 0.31$ \\
\hline $16-20 y r s ~ N=3$ & $27.33 \pm 3.0$ & $0.41 \pm 0.05$ \\
\hline p-value & $<0.0001$ & $<0.0001$ \\
\hline
\end{tabular}

Table 2 Results of SOD and GPx levels show a significant difference $(p<0.05)$ when compared in diabetics with respect to duration of illness. It shows a significant decrease in the levels of the enzymes with increasing years of illness. ANOVA values of SOD and GPx levels in diabetic subjects with respect to duration of illness are further illustrated with a line graph as shown in Figures below. 


\section{International Journal of Science and Research (IJSR) \\ ISSN (Online): 2319-7064}

Index Copernicus Value (2013): 6.14 | Impact Factor (2014): 5.611

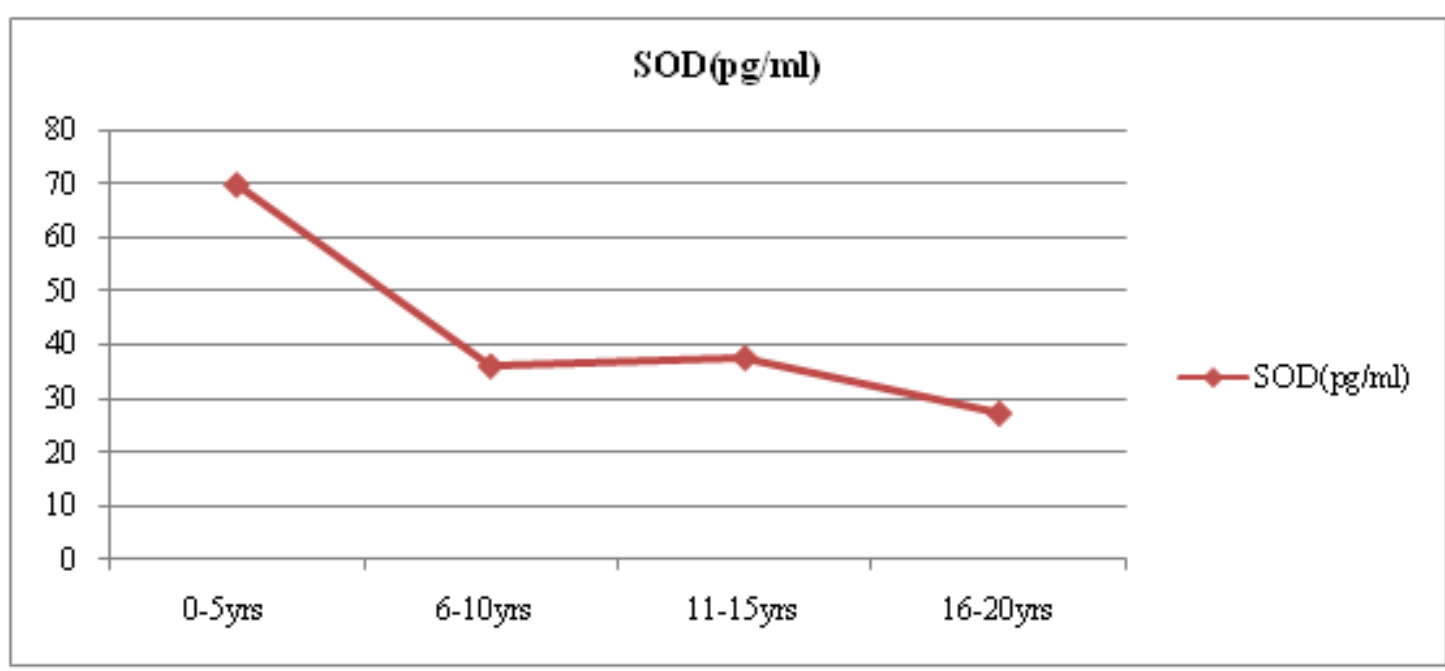

Figure 1: A line graph showing SOD levels in diabetics with respect to duration of illness.

The line graph shows decreasing SOD levels with respect to increasing years of illness. From a mean concentration of $69.98 \mathrm{pg} / \mathrm{ml}$ for subjects who have had Type $2 \mathrm{DM}$ for the period of $0-5$ years, it decreased to $36.16 \mathrm{pg} / \mathrm{ml}$ (6-10years), then a little spike reaching $37.70 \mathrm{pg} / \mathrm{ml}$ for subjects who have had it for the period of 11-15 years and finally falling down to $27.33 \mathrm{pg} / \mathrm{ml}$ for subjects who have had it for $16-20$ years.

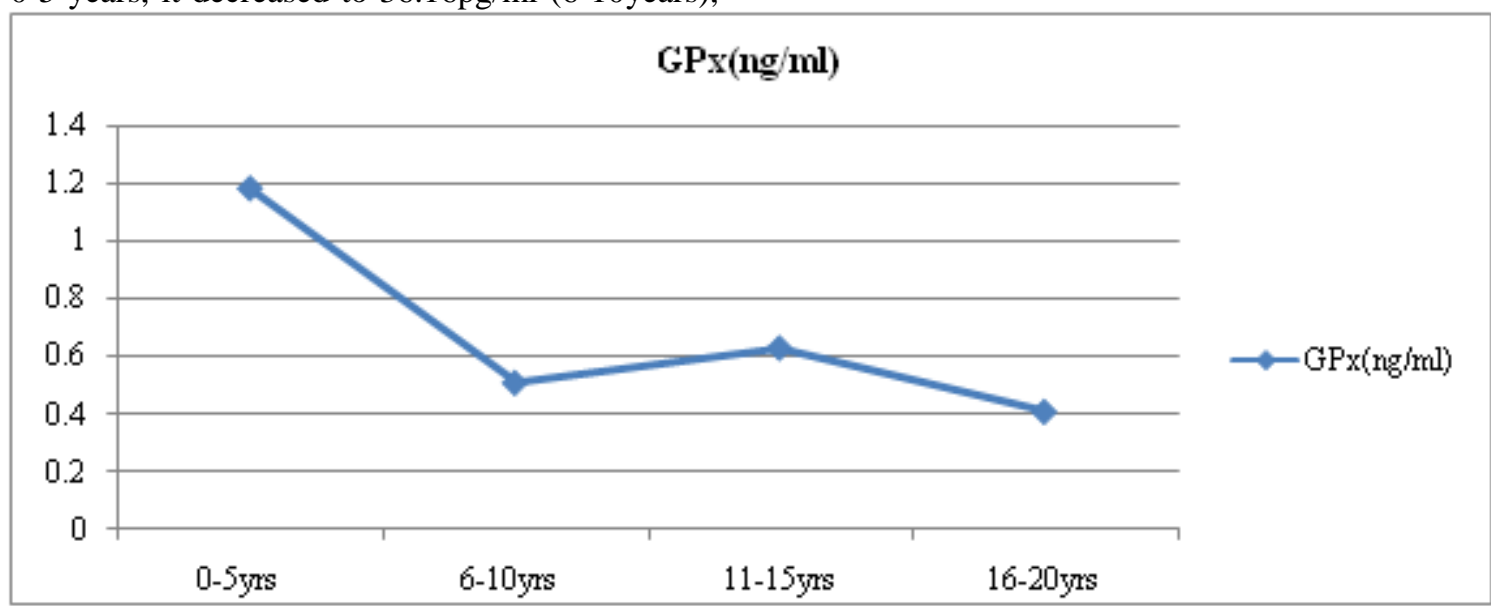

Figure 2: A line graph showing GPx levels in diabetics with respect to duration of illness.

The line graph shows decreasing GPx levels with respect to increasing years of illness. From a mean concentration of $1.18 \mathrm{ng} / \mathrm{ml}$ for subjects who have had Type $2 \mathrm{DM}$ for the period of $0-5$ years, it decreased to $0.51 \mathrm{ng} / \mathrm{ml}$ (6-10years), then a little spike reaching $0.63 \mathrm{ng} / \mathrm{ml}$ for subjects who have had it for the period of 11-15 years and finally falling down to $0.41 \mathrm{ng} / \mathrm{ml}$ for subjects who have had it for $16-20$ years.

Table 3: Showing ANOVA results of SOD and GPx values in diabetic subjects with respect to different age groups.

\begin{tabular}{|c|c|c|}
\hline Age(yrs) & SOD $(\mathrm{pg} / \mathrm{ml})$ & GPx(ng/ml) \\
\hline $21-30 \mathrm{yrs} \mathrm{N}=9$ & $59.47 \pm 24.42$ & $0.86 \pm 0.69$ \\
\hline $31-40 \mathrm{yrs} \mathrm{N}=23$ & $52 \pm 27.94$ & $0.82 \pm 0.56$ \\
\hline
\end{tabular}

\begin{tabular}{|c|c|c|}
\hline 41-50yrs N=25 & $49.94 \pm 27.23$ & $0.75 \pm 0.51$ \\
\hline 51-60yrs N=28 & $45.57 \pm 18.72$ & $0.72 \pm 0.48$ \\
\hline 61yrs and above $\mathrm{N}=24$ & $42.07 \pm 22.09$ & $0.70 \pm 0.41$ \\
\hline p-value & $>0.05$ & $>0.05$ \\
\hline
\end{tabular}

The results in Table 3 show a downward trend in SOD and GPx levels as the age of the subjects increases, although not significant $(\mathrm{p}>0.05)$.

ANOVA values of SOD and GPx levels in diabetic subjects with respect to different age groups are further illustrated with a line graph as shown in Figures below. 
International Journal of Science and Research (IJSR)

ISSN (Online): 2319-7064

Index Copernicus Value (2013): 6.14 | Impact Factor (2014): 5.611

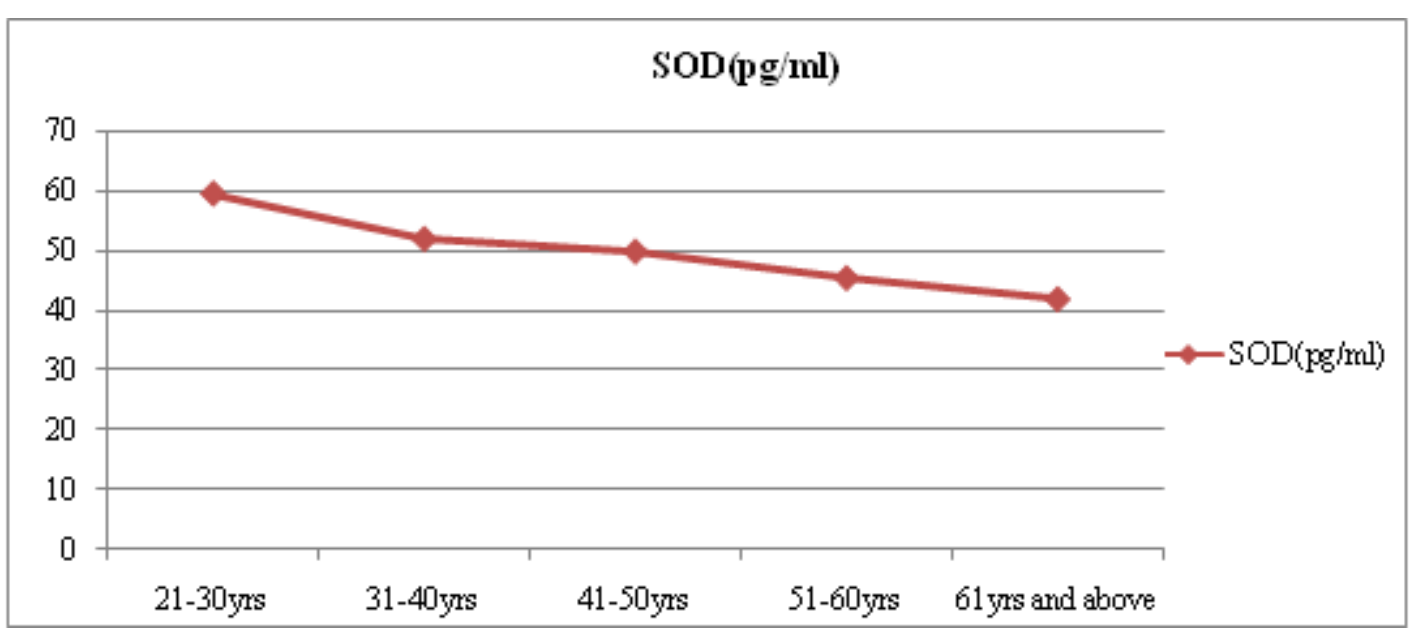

Figure 3: A line graph showing SOD levels in diabetics with respect to age groups.

The line graph shows SOD levels in the diabetic subjects decreased with advancing years. From a value of $59.47 \mathrm{pg} / \mathrm{ml}$ for age group 21-30years it decreased to $52.00 \mathrm{pg} / \mathrm{ml}$ for age group $31-40$ years, then $49.94 \mathrm{pg} / \mathrm{ml}$ for age group 41 - 50years. It further went down to $45.57 \mathrm{pg} / \mathrm{ml}$ for age group $51-60 y e a r s$ and finally dropping to $42.07 \mathrm{pg} / \mathrm{ml}$ for those who are 61 years and above.

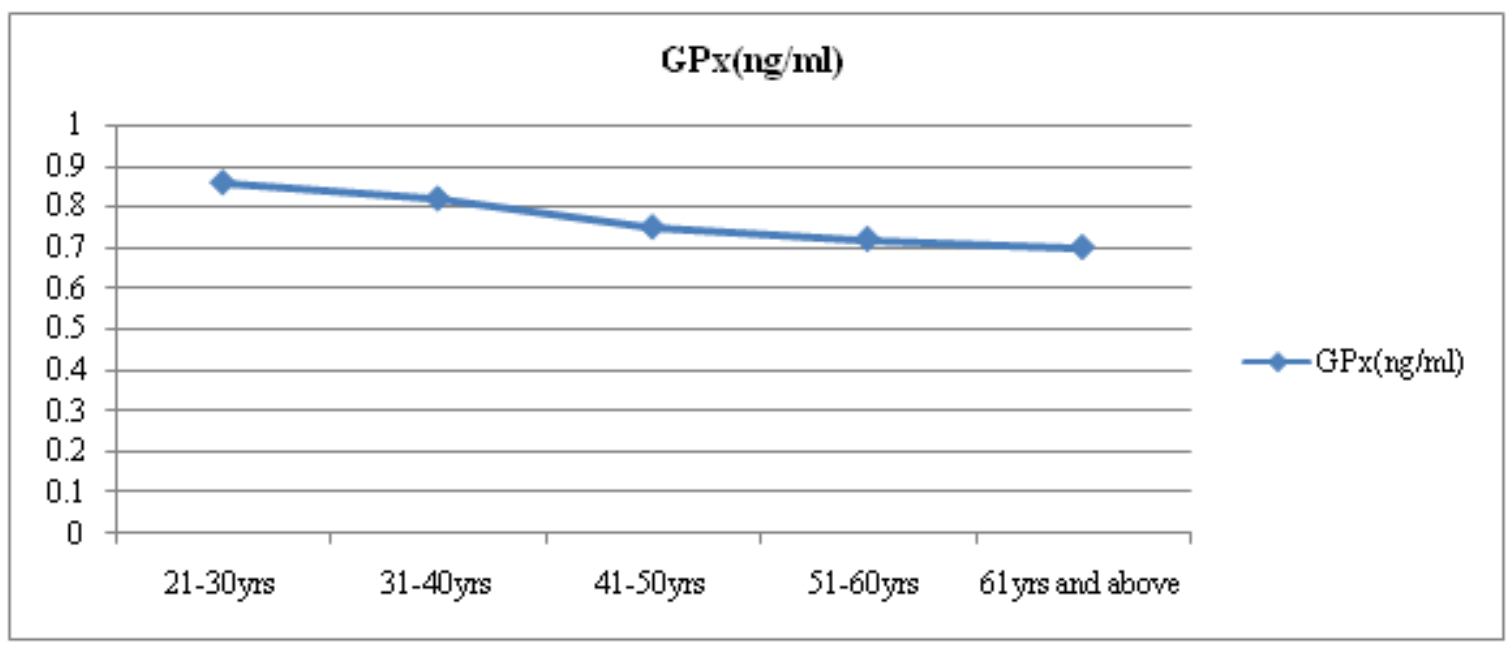

Figure 4: A line graph showing GPx levels in diabetics with respect to age groups

The line graph shows GPx levels in the diabetic subjects decreased with advancing years. From a concentration of $0.86 \mathrm{ng} / \mathrm{ml}$ for age group 21-30years it decreased to $0.82 \mathrm{ng} / \mathrm{ml}$ for age group 31-40years, then $0.75 \mathrm{ng} / \mathrm{ml}$ for age group 41-50years. It further went down to $0.72 \mathrm{ng} / \mathrm{ml}$ for age group 51-60years and finally dropping to $0.70 \mathrm{ng} / \mathrm{ml}$ for those who are 61years and above.

\section{Discussion}

The results from this study showed that the mean values of FBS and HbA1c for Type 2 diabetics were significantly higher $(p<0.05)$ when compared with that of the control subjects as shown in Table 1. HbA1c(\%) levels of $8.65 \pm$ 2.21 for the test group as against $5.48 \pm 0.57$ for the control group show the degree of glycaemia in the test group, which could be attributed to deteriorating the beta-cell function in diabetics resulting in relative or absolute insulin deficiency and hyperglycaemia in the face of insulin resistance (Fonseca, 2009).

The levels of the antioxidant enzymes SOD and GPx were found to be significantly lower in the diabetics $(p<0.05)$ than that of the control subjects as shown in Table 1. These findings show that Type 2 diabetes maybe associated with decrease in antioxidant enzyme levels resulting from increased oxidative stress. This agrees with the findings of Djordjevi. et al., 2011, in which they discovered a reduced systemic anti-oxidative defence in patients with Type 2 diabetes mellitus. Our findings are also in line with findings of Matkovics et al., 1982, who discovered reduced erythrocyte SOD activity in diabetics as compared to nondiabetics. Uzel et al., 1987 also found impaired GPx activity and lower erythrocyte GSH in Type 2 diabetic patients.

The finding in this study also reveal a significant difference $(p<0.05)$ in the levels of the antioxidant enzymes SOD and GPx in diabetics with respect to duration of illness. As shown in Table 2, it shows significantly decreasing SOD and GPx levels with increasing years of illness, with the decrease most evident in those affected for the period of 16-20years. Thus, this shows decreasing antioxidant status with increasing years of Type $2 \mathrm{DM}$. This could be the result of increased production of ROS and also increased glycation of the enzymes. This is in line with the study carried out by Prechl et al., 1997 in which they found reduced erythrocyte 


\section{International Journal of Science and Research (IJSR) \\ ISSN (Online): 2319-7064 \\ Index Copernicus Value (2013): 6.14 | Impact Factor (2014): 5.611}

SOD activity in patients who had diabetes for more than 10 years compared to those whose disease was not so longstanding. Our findings also agree with the work of Djordjevi. et al., 2011, in which they found decreasing SOD and GPx activities with advancing years of illness.

Also shown in Table 2, Figure 1 and 2 are variable reductions in the levels of the antioxidant enzymes SOD and GPx with respect to duration of illness with patients who have suffered the disease for 11-15 years having a slight increase compared to those affected for 6-10 years and the last group affected for 16-20 years. This could be explained as an adaptive or compensatory response of the antioxidative system. It agrees with the study of Djordjevi. et al., 2011, in which they studied the activities of SOD and GPx in diabetics having the illness for a period of $0-5$ years, 5-15 years and 15 years and above. In there study, patients having the disease for 5-11 years had a slight increase in SOD activity as compared to the other two groups.

Our findings also reveal decreasing levels of the antioxidant enzymes SOD and GPx with increasing ages of the diabetic subjects as shown in Table 3, Figure 3 and 4, with the highest level found in the diabetics within the age bracket of 21-30 years and the least enzyme level found in affected patients who are 61 years and above. This reduction is though not significant. This finding agrees with the findings of Bohr et al., 1998, in which they reported an increase in mitochondrial ROS production and diminished endogenous antioxidant activity in aging individuals. It also agrees with the literature of Poljsak \& Milisav, 2013, in which they went further to state that excessive production of ROS and reduced antioxidant defence with age significantly contribute to aging.

\section{Conclusion}

The findings in this study revealed depressed anti-oxidant status in Type 2 diabetics as compared to apparently healthy non-diabetics. This is because the levels of the antioxidant enzymes SOD and GPx were significantly lower in the diabetics. The levels of the antioxidant enzymes SOD and GPx were discovered to be more depressed as the duration of diabetes increased, implying an increase in ROS production and/or increased glycation of the antioxidant enzymes that further suppresses the anti-oxidative system and even its adaptive responses, thus exposing Type 2 diabetic patients to increased cellular damage by oxidative stress. Our findings also reveal a non significant decrease in the levels of SOD and GPx in the diabetics with aging, and other literatures have associated aging with increased production of free radicals.

In conclusion, Type 2 diabetes is associated with decreased antioxidative status as the levels of the antioxidant enzymes SOD and GPx were significanlty reduced in the diabetic subjects. The increasing duration of the illness further depresses the antioxidative system, that is, as the disease condition progresses, antioxidative parameters are further depleted. Hyperglycaemia and increased generation of ROS depresses the endogenous antioxidant defence system in Type 2 diabetics, exposing cells to damage from oxidative stress which could lead to the development of diabetic complications.

It is hereby recommended that antioxidative therapy be incorporated in the management/therapy of Type 2 diabetics, to supplement the endogenous anti-oxidative system, as this could prevent or delay progression of the disease and the development of late diabetic complications.

\section{References}

[1] American Diabetes Association. (2010). Diagnosis and classification of diabetes mellitus. Diabetes Care, 33(1), 62-69.

[2] Shaw, J. E., Sicree, R. A., \& Zimmet, P. Z. (2010). Global estimates of the prevalence of diabetes for 2010 and 2030. Diabetes Research and Clinical Practice, 87(1), 4-14.

[3] Brownlee, M. (2001). Biochemistry and molecular cell biology of diabetic complications. Nature, 414(6865), 813-820.

[4] Rains, J. L., \& Jain, S. K. (2011). Oxidative stress, insulin signaling, and diabetes. Free Radical Biology and Medicine, 50(5), 567-575.

[5] Montonen, J., Knekt, P., Jarvinen, R., \& Reunanen, A. (2004). Dietary antioxidant intake and risk of type 2 diabetes. Diabetes Care, 27, 362-366.

[6] Mark, P. (1998). Antioxidants. Clinical Nutrition Insights, 31, 01-04.

[7] Krishnamurthy, P., \& Wadhwani, A. (2012). Antioxidant enzymes and human health. In; M.A. ElMissiry (Ed.), Antioxidant enzyme (pp. 3-18). Rijeka, Croatia: InTech.

[8] Bashan, N., Kovsan, J., Kachko, I., Ovadia, H., \& Rudich, A. (2009). Positive and negative regulation of insulin signaling by reactive oxygen and nitrogen species. Physiological Reviews, 89, 27-71.

[9] Rhodes, C. J. (2005). Type 2 diabetes-a matter of betacell life and death? Science, 307(5708), 380-384.

[10] Mahadev, K., Motoshima, H., Wu, X., Ruddy, J. M., Arnold, R. S., \& Cheng, G. (2004). The NAD(P)H oxidase homolog Nox4 modulates insulin-stimulated generation of $\mathrm{H}_{2} \mathrm{O}_{2}$ and plays an integral role in insulin signal transduction. Molecular and Cell Biology, 24(5), 1844-1854.

[11] Bloch-Damti, A., \& Bashan, N. (2005). Proposed mechanisms for the induction of insulin resistance by oxidative stress. Antioxidants and Redox Signalling, 7(11-12), 1553-1567.

[12] Buse, M. G. (2006). Hexosamines, insulin resistance, and the complications of diabetes: Current status. American Journal of Physiology, Endocrinology and Metabolism, 290(1), 1-8.

[13] Tiedge, M., Lortz, S., Drinkgern, J., \& Lenzen, S. (1997). Relation between antioxidant enzyme gene expression and antioxidative defense status of insulinproducing cells. Diabetes, 46(11), 1733-1742.

[14] Brownlee, M. (2003). A radical explanation for glucoseinduced beta cell dysfunction. Journal of Clinical Investigation, 112(12), 1788-1790.

[15] Kaneto, H., Matsuoka, T. A., Nakatani, Y., Kawamori, D., Matsuhisa, M., \& Yamasaki, Y. (2005). Oxidative 


\section{International Journal of Science and Research (IJSR) \\ ISSN (Online): 2319-7064 \\ Index Copernicus Value (2013): 6.14 | Impact Factor (2014): 5.611}

stress and the JNK pathway in diabetes. Current Diabetes Reviews, 1(1), 65-72.

[16] Kaneto, H., Xu, G., Song, K.H., Suzuma, K., BonnerWeir, S., \& Sharma, A. (2001). Activation of the hexosamine pathway leads to deterioration of pancreatic beta-cell function through the induction of oxidative stress. Journal of Biological Chemistry, 276(33), 31099-31104.

[17] Rizzo, M. A., \& Piston, D. W. (2003). Regulation of beta cell glucokinase by S-nitrosylation and association with nitric oxide synthase. Journal of Cell Biology, 161(2), 243-248.

[18] Drews, G., Krippeit-Drews, P., \& Dufer, M. (2010). Oxidative stress and beta-cell dysfunction. Pflugers Arch, 460(4), 703-718.

[19] Nishikawa, T., Edelstein, D., Du, X.L., Yamagishi, S., Matsumura, T., \& Kaneda, Y. (2000). Normalizing mitochondrial superoxide production blocks three pathways of hyperglycemic damage. Nature, 404, 787790.

[20] Ihara, Y., Toyokuni, S., Uchida, K., Odaka, H., Tanaka, T., Ikeda, H., Hiai, H., Seino, Y., \& Yamada, Y. (1999). Hyperglycemia causes oxidative stress in pancreatic beta-cells of GK rats, a model of type 2 diabetes. Diabetes, 48, 927-932.

[21] Kaneto, H., Fujii, J., Myint, T., Miyazawa, N., Islam, K. N., Kawasaki, Y., Suzuki, K., Nakamura, M., Tatsumi, H., Yamasaki, Y., \& Taniguchi, N. (1996). Reducing sugars trigger oxidative modification and apoptosis in pancreatic $\beta$-cells by provoking oxidative stress through the glycation reaction. Biochemical Journal, 320, 855-863.

[22] Rolo, A. P., \& Palmeira, C. M. (2006). Diabetes and mitochondrialfunction: Role of hyperglycemia and oxidative stress. Toxicology and Applied Pharmacology, 212, 167-78.

[23] World Health Organisation. (2011). Use of glycated haemoglobin (HbA1c) in the diagnosis of diabetes mellitus. Abbreviated Report of a WHO Consultation. Geneva.

[24] American Diabetes Association. (2015). Standards of medical care in diabetes. Diabetes Care, 38(1), 01-93.

[25] Fonseca, V. A. (2009). Defining and characterizing the progression of type 2 diabetes. Diabetes Care, 32(2), 151-155.

[26] Djordjević, G. M., Djurić, S. S., Djordjević, V. B., Apostolski, S., \& Živković, M. (2011). The role of oxidative stress in pathogenesis of diabetic neuropathy: erythrocyte superoxide dismutase, catalase and glutathione peroxidase level in relation to peripheral nerve conduction in diabetic neuropathy patients. In: C. Croniger (Ed.), Role of the Adipocyte in Development of Type 2 Diabetes. (pp 153-172). Rijeka, Croatia: InTech.

[27] Matkovics, B., Varga, SzI., Szabo, L., \& Witas, H. (1982). The effect of diabetes on the activities of the peroxide metabolism enzymes. Hormone and Metabolic Research, 14, 77-79.

[28] Uzel, N., Sivas, A., Uysal, M., \& Oz, H. (1987). Erythrocyte lipid peroxidation and glutathione peroxidase activities in patients with diabetes mellitus. Hormone and Metabolic Research, 19, 89- 90.
[29] Prechl, J., Szaleczky, E., Pusztai, P., Kocsis, I., Tulassay, Z. S., \& Somogyi, A. (1997). Effect of clinical duration of diabetes mellitus on various antioxidants in blood. Medical Science Monitor, 3, 167-170.

[30]Bohr, V., Anson, S., Mazur, R. M., \& Dianov, G. (1998). Oxidative DNA damage processing and changes with aging. Toxicology Letters, 102-103, 47-52.

[31] Poljsak, B., \& Milisav, I. (2013). Aging, oxidative Stress and antioxidants. In: J.A. Morales-Gonzalez (Ed.), Oxidative stress and chronic degenerative diseases: A role for antioxidants (pp. 345). Rijeka, Croatia: InTech. 